\title{
Deconstructivist Interaction Design: Interrogating Expression and Form
}

\author{
Martin Murer \\ Center for HCI \\ University of Salzburg \\ martin.murer@sbg.ac.at
}

\author{
Verena Fuchsberger \\ Center for HCI \\ University of Salzburg \\ verena.fuchsberger@sbg.ac.at
}

\author{
Manfred Tscheligi \\ Center for HCI \\ University of Salzburg \\ manfred.tscheligi@sbg.ac.at
}

\begin{abstract}
In this paper, we propose deconstructivist interaction design in order to facilitate the differentiation of an expressional vocabulary in interaction design. Based on examples that illustrate how interaction design critically explores (i.e., deconstructs) its own expressional repertoire, we argue that there are commonalities with deconstructivist phases in related design disciplines to learn from. Therefore, we draw on the role and characteristics of deconstructivism in the history of architecture, graphic design, and fashion. Afterwards, we reflect on how interaction design is already a means of deconstruction (e.g., in critical design). Finally, we discuss the potential of deconstructivism for form-giving practices, resulting in a proposal to extend interaction design's expressional vocabulary of giving form to computational material by substantiating a deconstructivist perspective.
\end{abstract}

\section{Author Keywords}

Deconstructivism; Interaction Design; Styles; Aesthetics

\section{ACM Classification Keywords}

H.5.m. Information Interfaces and Presentation (e.g. HCI): Miscellaneous

\section{INTRODUCTION}

A motion controlled fur monkey makes a spectator realize, that she has been acting like a chimpanzee for the last couple of minutes [20]. Strangers sitting on a public bench unconsciously slip closer as the bench slowly changes its shape [13]. A whole room responds to the movements of a person by moving, collapsing, or expanding [22]. A lightbulb throws a shadow on a wall and all of a sudden the shadow grows wings and starts to fly [15]. These four encounters with interactive technology, all presented at recent premier HCI venues, share certain characteristics that are denotive to a current strand in interaction design, which shifts attention from function to expression. At first glance, the salient communality is that the four artefacts bear a surprising momentum, they are exceptional, rather a piece than a system. Less salient is that they all critically explore form-giving in interaction design by focusing their exploration on computation as a design material, they deconstruct our assumptions about how to interact with a particular element in our reality.

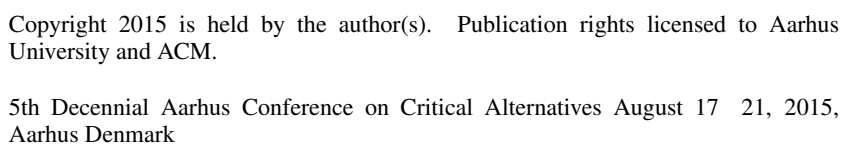

According to Vallgårda [23], giving form to computational materials in interaction design is a practice that comprises three elements: the physical form, the temporal form, and the interaction gestalt. As the computer is no longer at the center of attention, and as interaction design is no longer just a matter of interface design, Vallgårda proposed to establish a form-giving practice of interaction design. In order to develop such a practice, we need to explore and detail the according expressional vocabulary. Interaction design though does not start to develop its form-giving practice and expressional repertoire from scratch. As Hallnäs and Redström [10] argue, human-computer interaction has to some extent adopted rudimentary aesthetics from other areas, such as graphic design. Those design disciplines are highly relevant in HCI, for instance, in screen-dominated interaction design. This is considered insufficient, as the aesthetics

[...] of disciplines dominated by design-by-drawing tells us very little about the computational aspects of this new material we are working with. [10, p. 106]

We propose to look at historically evolved practices that enriched the aesthetic vocabulary of related design disciplines, such as architecture, graphic design, and fashion. In particular, we draw attention to deconstructive phases, as those share characteristics with the contemporary shift in interaction design from a pure focus on function to an increased attention to expressional possibilities (e.g., in form-driven ixd research [12]). We will depict the relation between deconstructivism and established design disciplines and discuss how interaction design is already in the service of deconstruction (e.g., in critical design). Finally, we will conclude with a proposal for substantiating a deconstructive perspective in interaction design that might enrich its expressional repertoire by interrogating the form of computational material.

\section{DECONSTRUCTIVISM AND DESIGN}

In a 2013 event the New York Museum of Modern Arts (MoMA) celebrated the 25th anniversary of a milestone exhibition in architecture: Philip Johnson and Mark Wigley had curated "Deconstructivist Architecture", showcasing the work of seven at the time of the exhibition contemporary architects (see e.g., [11]). The curators did not attempt to define a style; they rather aimed to present then contemporal architecture of similar approaches. Still, it was that very exhibition that has coined the term deconstructivism as a framing for a highly influential development in architecture and many other disciplines in succession. The visual appearance of deconstructivist styles can be characterized by controlled 
chaos, unpredictability and distortion. Underneath its skin, deconstruction is not about a style or a movement. Rather, its proponents understand their work as an opposition to the ordered rationality of postmodernism.

\section{Origins of Deconstructivist Movements}

Being based on Jacques Derrida's philosophic concept of deconstruction, deconstructivism in architecture asks questions about modernism by "reexamining its own language, materials, and processes," [16] as summarised by Wigley in his 1988 catalogue essay:

A deconstructive architect is [...] not one who dismantles buildings, but one who locates the inherent dilemmas within buildings. The deconstructive architect puts the pure forms of the architectural tradition on the couch and identifies the symptoms of a repressed impurity. The impurity is drawn to the surface by a combination of gentle coaxing and violent torture: the form is interrogated. [16]

It was that MoMA exhibition in 1988 that got deconstructivism "catapulted into design press" [16], with a lasting impact not only on architecture. Other disciplines such as graphic design (e.g., [18]) or fashion (e.g., [14]) soon augmented existing streams with those formal concepts and mechanisms. Deconstructivism became a kind of cliché of a certain formal style, characterized by aggressive arrangements, sharp edges, fragmentation, etc. Deconstruction got phrased more generally as means "[...] to deform a rationally structured space so that the elements within that space are forced into new relationships" [18, p. 122]. In graphic design and fashion the notion of deconstruction since changed from a style to an activity of critical form-giving, becoming a central element in any design practice $[16,14]$. It is no longer en vogue but rather considered a zeitgeist (e.g., [6]). The contemporary relevance of deconstructing is though still present. As Derrida phrased it in a 1994 interview in The New York Times Magazine, there is some element in deconstruction "that belongs to the structure of history or events. It started before the academic phenomenon of deconstruction, and it will continue with other names." [21]

All these deconstructive movements have passed their peak of attention, but they left their respective disciplines with an enriched set of formal vocabulary. Taking this deconstructivist perspective, it may be worthwhile to consider how it relates to the goal of establishing a richer expressional vocabulary for form-giving practices in interaction design. A deconstructivist lens can help us understand what kind of deconstruction we already perform in interaction design, how we invert existing approaches and thinking, and how this framing might support both the practice and theory in order to understand and link their approaches to experiential knowledge creation. Similar to architecture, graphic design, and fashion, interaction design is in the first place concerned with construction. However, notions of deconstructivism, such as provocation, critical theory and design are pervading interaction design, being a mode of questioning the current state of the art. Both creating an enhanced understanding as well as imagining and developing future interactive systems are reasonable and desirable outcomes of such approaches.

\section{Interaction design in the service of deconstruction}

The background of our proposal is, on one hand, constituted by the origin of deconstructivist movements, such as philosophy, architecture and graphic design. On the other hand, there is also related work in interaction design and HCI, which to varying extents includes deconstructivist elements as part of a method or thinking. With HCI becoming more implicated in culture [4], recent practices and concepts can be identified that incorporate deconstruction as a means to raise awareness for societal changes and issues, such as critical theory, critical design, or feminist design.

The study object of critical theory is, broadly speaking, any aspect of culture, exploring the constructedness of knowledge [1]. For HCI, Bardzell [1] suggests ways for criticism to contribute to its practice. Critical design [8] is an approach to provocation, which offers sources and strategies to inspire designs, such as techniques to radically rethink fundamental concepts. Those strategies aim at reconfiguring sociocultural norms in more aesthetic or social ways and may stimulate demand for such designs [3]. From this point of view, the deconstructive moment is de- and reconstructing knowledge.

Feminism can also be considered from a deconstructivist point of view. Following the political agenda of critiquing power (e.g., [5]), its aim is to deconstruct social structures. In HCI, for instance, feminist thinking supports the awareness and accountability of its social and cultural consequences [2]. Buchmüller argues that one common goal of feminism is to "[C]hange the situation/position of the researched by offering them critical ways of thinking, new ways of expression as well as new opportunities of action.” [5, p. 175]. This means that feminism seeks to initiate social change by changing social structures. Deconstruction in a feminist tradition is, thus, applying deconstructive procedures to dominant gender structures [25]. The deconstructive element is related to the artifact [1] which initiates questioning a social setting.

Besides critical design and feminism, a further notion of deconstructing the social by means of technology can be found in critical making. It emphasizes critique and expression rather than technical sophistication and function [17]. Making is understood as an activity, which is a vehicle for critically engaging with the world [9]. The constructive processes are considered as the site for analysis, the shared acts of making are more important than the evokative artifacts. Thus, the prototypes are a means to an end, which achieve value by creating, discussing and reflecting on them [17].

\section{DECONSTRUCTIVIST INTERACTION DESIGN}

With deconstructivist interaction design we seek to frame critical practices that emphasize the expressional possibilities interaction design provide. This is not mutually exclusive from other critical practices in human-computer interaction and design, i.e., a particular design or artefact may well satisfy multiple attributions. While, e.g., critical design aims to "introduce both designers and users to new ways of looking at the world and the role that designed objects can play for them 
in it" [19, p. 51], we want to draw attention to the form-giving and material aspects. As Hallnäs and Redström [10] argue, in HCI-related research and design practice aesthetical decisions tend to be hidden by concerns for practical functionality, usability, user requirements etc. In line with Dunne [7], they argue, that those decisions are hidden, "not because they are not made, but because the expressions of the things we design become mere consequences of other concerns." [10, p. 105] They propose a program for experimental design of computational things that turns the classical leitmotif "form follows function" upside down. While not explicated by Hallnäs and Redström, we argue that their program bears a deconstructive momentum: As a critical activity the classical design agenda is questioned by proposing an alternative leitmotif, i.e., function resides in the expression of things.

As "form follows function" used to be the prevailing (structuralist) leitmotif of interface design, "function resides in the expression of things" may become a (deconstructive) leitmotif of interaction design. It would guide explorations that question the expressional qualities of materials and artefacts. It implies engagement with the expressional repertoire, its articulation and vocabulary. Furthermore, deconstructive design can help to extend the existing repertoire by critically challenging and examining what is already known.

\section{Exemplary Deconstructivist Interaction Design}

In the following we describe one of the artefacts highlighted in the very beginning of this paper in order to elaborate on how it bears a deconstructive stance. Remnance of Form by Leigh and colleagues [15] is an interactive installation that aims to explore the "dynamic tension between an object and its shadow." [15, p. 411] Composed of a light, projection and tracking technology, a shadow can detach itself from its former role. The relationship between a light bulb, an object and its shadow is constantly modulated and distorted. A person interacting with Remnance of Form can move the light bulb and the object around in physical (and temporal) space. Depending on one's movements in respect to the installation, the shadow, as a digital alteration of reality, is programmatically shaped into different forms and behaviours (i.e., changes shape, grows wings and flies away, shows fear).

Remnance of Form deconstructs our perception and assumptions about interacting with reality. It is critical in the sense that it deforms the elements of what used to be a rationally structured space (i.e., our previous assumptions about the interaction with a light bulb, an object and its shadow) and forces them into new relationships. Arguably, its critical momentum does though not seek to "disrupt or transgress social and cultural norms" [3] as framed by critical design. Rather it is the interdependence of the form elements of interaction design [23] that are interrogated and explored at once. This adds a particular expression to our interaction design vocabulary, one that can easily be interpreted as being magical through dissolving the formerly stable associations between lights, objects and their shadows. The interaction gestalt of Remnance of Form as it unfolds through interaction, its disruptive and disturbing nature, was brought on by a balanced in- tegration of physical and temporal form into a coherent entity while breaking with the assumptions of how reality behaves.

Following Vallgårda's trinity of forms (physical form, temporal form, interaction gestalt) in interaction design practice [23], the core, the interplay between the three, is what Leigh et al. [15] challenged in their design. Deconstructivist interaction design, however, may also deconstruct single elements as well. In order to question the physical form, the related design disciplines provide a whole spectrum of practices and vocabulary to draw on, as they already intensively explored the expressional repertoire of physical forms, for instance, in architecture, pottery, or statuary. Challenging, articulating, and expressing the temporal form or the interaction gestalt, however, is an exercise interaction design is necessarily engaged with in interrogating the interplay of the three formgiving elements. Looking through a deconstructivist lens at interaction design practices and the related artefacts, whether they are meant to be deconstructive or not (or, for instance, following a critical, feminist or any other approach), may support this exercise and contribute to the articulation of formal expressional vocabulary.

\section{DISCUSSION AND CONCLUSION}

Starting from architectural deconstructivism, we argue that framing interaction design examples and strands from a deconstructivist perspective supports reflection on the act of taking apart form, function, meaning, concepts, or artifacts to enhance our knowledge and expressional vocabulary for a form-giving practice in interaction design.

The reflection we presented is meant to be a starting point for a discussion on deconstructive interaction design by trying to consider current design practices through a deconstructivist lens. In order to strengthen this framing, further material and design studies and examinations from this perspective will be needed that support the sophistication of (deconstructive) form-giving practices. While there are obvious parallels to deconstructive phases in other disciplines, deconstructive interaction design underlies multiple deviations that are constituted in the constant advancement of computational technology. This prompts interaction design to continuously challenge and deconstruct established computational forms (e.g., as the predominate aesthetics of GUIs brought about a deconstruction of form, questioning whether "a machine needed to be visible at all.' $[24$, p. 67])

In that realm we do not consider deconstructive interaction design being tied to a political agenda, as in critical or feminist theory; rather, we aim to emphasize the act of questioning (material) form and functions. We do not oppose deconstruction to construction; instead, we see deconstruction as a means to gain an additional kind of knowledge, one, that allows to derive multiple functions out of form, both conceptually and practically. The framing of deconstructivist interaction design is no opposition to the epistemological value of prevailing critical practices in human-computer interaction, nor to constructive design research. Rather, we aim to draw attention to the potential of critical form-giving as means to enrich and further detail the expressional vocabulary of interaction design practice. Drawing on a notion Johnson used to 
describe the then contemporary architecture, deconstructivist interaction design can be described as a "contemporary artistic phenomenon that derives its forms from constructivism and yet deviates from it." [11]

\section{ACKNOWLEDGMENTS}

The financial support by the Austrian Federal Ministry of Science, Research and Economy and the National Foundation for Research, Technology and Development is gratefully acknowledged (Christian Doppler Laboratory for "Contextual Interfaces").

\section{REFERENCES}

1. Jeffrey Bardzell. 2009. Interaction criticism and aesthetics. In Proc. CHI 2009 (CHI '09). ACM, New York, NY, USA, 10. DOI :

http://dx.doi.org/10.1145/1518701.1519063

2. Shaowen Bardzell and Jeffrey Bardzell. 2011. Towards a feminist HCI methodology: social science, feminism, and HCI. In Proc. CHI 2011. ACM, 10. DOI : http://dx.doi.org/10.1145/1978942.1979041

3. Shaowen Bardzell, Jeffrey Bardzell, Jodi Forlizzi, John Zimmerman, and John Antanitis. 2012. Critical design and critical theory: the challenge of designing for provocation. In Proc. DIS '12. ACM, 10. DOI : http://dx.doi.org/10.1145/2317956.2318001

4. Mark Blythe, Jeffrey Bardzell, Shaowen Bardzell, and Alan Blackwell. 2008. Critical issues in interaction design. In Proc. BCS-HCI '08. BCS, UK, 2. http: //dl.acm.org/citation. cfm?id=1531826.1531880

5. S. Buchmueller. 2012. How can Feminism Contribute to Design? Reflexions about a feminist framework for design research and practice. In Design Research Society (DRS) International Conference.

6. Chuck Byrne and Martha Witte. 2001. A brave new world: understanding deconstruction. Graphic Design History (2001), 245.

7. Anthony Dunne. 1999. Hertzian tales. MIT press London.

8. Anthony Dunne and Fiona Raby. 2001. Design noir: The secret life of electronic objects. Springer.

9. Shannon Grimme, Jeffrey Bardzell, and Shaowen Bardzell. 2014. "We'Ve Conquered Dark": Shedding Light on Empowerment in Critical Making. In Proc. NordiCHI'14. ACM, New York, NY, USA, 10. DOI : http://dx.doi.org/10.1145/2639189.2641204

10. Lars Hallnäs and Johan Redström. 2002. Abstract information appliances: methodological exercises in conceptual design of computational things. In Proc. DIS'02. ACM, New York, NY, USA, 12. DOI : http://dx.doi.org/10.1145/778712.778730

11. Philip Johnson and Mark Wigley. 1988. Deconstructivist Architecture: The Museum of Modern Art, New York. Little, Brown.
12. Heekyoung Jung and Erik Stolterman. 2012. Digital Form and Materiality: Propositions for a New Approach to Interaction Design Research. In Proc. NordiCHI'12. ACM, 645-654. DOI : http://dx.doi.org/10.1145/2399016.2399115

13. Sofie Kinch, Erik Grönvall, Marianne Graves Petersen, and Majken Kirkegaard Rasmussen. 2014. Encounters on a Shape-changing Bench: Exploring Atmospheres and Social Behaviour in Situ. In Proc. TEI'14. ACM, New York, NY, USA, 233-240. DOI : http://dx.doi.org/10.1145/2540930.2540947

14. Gizem Kiziltunali. 2012. A deconstructive system: fashion. Konferenssiesitelmä. 4th Global Conference, Inter-Disciplinary. Net.

15. Sang-won Leigh, Asta Roseway, and Ann Paradiso. 2015. Remnance of Form: Altered Reflection of Physical Reality. In Proc. TEI'15. ACM, New York, NY, USA, 2. DOI :

http://dx.doi.org/10.1145/2677199.2690874

16. Ellen Lupton and J Abbott Miller. 1994. Deconstruction and graphic design: history meets theory. Visible language 28 (1994), 346-346.

17. Matt Ratto. 2011. Critical Making: Conceptual and Material Studies in Technology and Social Life. The Information Society 27, 4 (2011), 252-260. DOI : http://dx.doi.org/10.1080/01972243.2011.583819

18. Timothy Samara. 2005. Making and breaking the grid: a graphic design layout workshop. Rockport Publishers.

19. Phoebe Sengers, Kirsten Boehner, Shay David, and Joseph 'Jofish' Kaye. 2005. Reflective Design. In Proc. $C C$ '05. ACM, New York, NY, USA, 10. DOI : http://dx.doi.org/10.1145/1094562.1094569

20. Jan M. Sieber and Ralph Kistler. 2013. Monkey Business. In Proc. TEI'14. ACM, New York, NY, USA, 2. DOI : http://dx.doi.org/10.1145/2540930.2555203

21. Mitchell Stephens. 1994. Jacques Derrida and Deconstruction. The New York Times Magazine, January 23. (1994).

22. Anna Vallgårda. 2014a. The Dress Room: Responsive Spaces and Embodied Interaction. In Proc. NordiCHI'14. ACM, New York, NY, USA, 10. DOI : http://dx.doi.org/10.1145/2639189.2639254

23. Anna Vallgårda. 2014b. Giving Form to Computational Things: Developing a Practice of Interaction Design. Personal Ubiquitous Comput. 18, 3 (March 2014), 577-592. DOI : http://dx.doi.org/10.1007/s00779-013-0685-8

24. Mikael Wiberg and Erica Robles. 2010. Computational compositions: Aesthetics, materials, and interaction design. International Journal of Design 4, 2 (2010), 65-76.

25. Peter V Zima. 2002. Deconstruction and critical theory. Continuum International Publishing Group. 